\title{
Evaluasi status kesuburan tanah sawah di Subak Kerdung dan Subak Kepaon, Kecamatan Denpasar Selatan
}

\section{Evaluation of paddy soil fertility status at the Subak Kerdung and Subak Kepaon, South Denpasar District}

\author{
Made Sri Sumarniasih ${ }^{1 *}$, Debora Desclarita Simanjuntak ${ }^{1}$, dan I Dewa Made Arthagama1 \\ ${ }^{1}$ Program Studi Agroekoteknologi, Fakultas Pertanian, Universitas Udayana \\ *Email korespondensi: sumarniasih@unud.ac.id
}

Diterima: 29 Juni 2021 / Disetujui: 20 Agustus 2021

\begin{abstract}
Soil fertility evaluation is the process of assessing nutrient problems in the soil and making fertilizer recommendations. The research is aimed at knowing the status of soil fertility in Subak Kerdung and Subak Kepaon, South Denpasar District, Denpasar City, as well as knowing the limiting factors and compiling directions for land fertility management based on the limiting factors of soil fertility in the research location. The research was carried out using survey method for soil sampling and soil analysis was carried out at the Laboratory of Soil and Environmental Sciences, Faculty of Agriculture, Udayana University. Parameters analyzed as a determinant of fertility status was CEC, BS, C-Organic, P-Total, K-Total with supporting data such as texture, water content and soil pH. Based on the results of the assessment of soil fertility status in Subak Kerdung and Subak Kepaon, South Denpasar, it is medium and high. Moderate fertility status is found in SLH III (Subak Kerdung) and IV (Subak Kepaon), while high fertility status is found in SLH I (Subak Kerdung), II (Subak Kerdung), and V (Subak Kepaon). The limiting factor in soil fertility status in Subak Kerdung and Subak Kepaon in SLH I, II, III, IV, and V was moderata P-total content, in SLH III and IV which were classification as moderata CEC. It is necessary to return crop residues or add organic matter to the soil, as well as the addition of fertilizers containing $P$ in the form of single fertilizers or compound fertilizers.
\end{abstract}

Keywords: soil fertility, paddy field, limiting factors, land management.

\section{ABSTRAK}

Evaluasi kesuburan tanah adalah proses penilaian masalah-masalah keharaan tanah dan pembuatan rekomendasi pemupukan. Penelitian dilakukan dengan tujuan untuk mengetahui status kesuburan tanah dan faktor pembatasnya, serta menyusun arahan pengelolaan kesuburan lahan. Penelitian dilakukan dengan metode survei untuk pengambilan sampel tanah dan selanjutnya tanah di analisis di laboratorium. Parameter yang dianalisa adalah KTK, KB, C-Organik, P-Total, K-Total dan data pendukung seperti tekstur, kadar air dan pH tanah. Berdasarkan hasil penilaian status kesuburan tanah di Subak Kerdung dan Subak Kepaon Denpasar Selatan adalah sedang dan tinggi. Status kesuburan sedang pada SLH III (Subak Kerdung) dan IV (Subak Kepaon), sedangkan status kesuburan tinggi terdapat pada SLH I (Subak Kerdung), II (Subak Kerdung), dan V (Subak Kepaon). Faktor pembatas dalam status kesuburan tanah di Subak Kerdung dan Subak Kepaon adalah kandungan P-total dan KTK yang tergolong sedang pada SLH III dan IV. Arahan pengelolaan kesuburan tanah adalah pengembalian sisa panen atau menambahkan bahan organik kedalam tanah dan penambahan pupuk yang mengandung unsur P dalam bentuk pupuk tunggal atau pupuk majemuk.

Kata kunci: kesuburan tanah, sawah, faktor pembatas, pengelolaan lahan.

\section{PENDAHULUAN}

Kesuburan tanah adalah potensi tanah menyediakan unsur hara dalam jumlah yang tersedia dan seimbang untuk menjamin pertumbuhan dan produksi tanaman yang optimum (Anna et al., 1985 dalam Yamani, 2010). Perlindungan Lahan Pertanian Pangan Berkelanjutan (PLP2B) adalah perlidungan dan proses dalam merencanakan, menetapkan, mengendalikan lahan pertanian pangan dan kawasannya secara berkelanjutan. Berdasarkan UU Nomor 41 Tahun 2009 Tentang PLP2B merupakan salah satu kebijakan pemerintah dalam mengendalikan laju alih fungsi lahan pertanian, khususnya sawah di Indonesia. Meningkatnya populasi penduduk menyebabkan terjadinya alih fungsi lahan sawah yang terdapat di Kecamatan Denpasar Selatan, dimana pada tahun 2002 luas lahan pertanian 977 ha hingga tahun 2019 menjadi 800 ha (BPS, 2019). Keadaan ini menyebabkan intensifikasi pertanian di lahan sempit perkotaan ini akan semakin bertambah seiring berjalannya waktu. Intensifnya penggunaan lahan di bidang pertanian akan menyebabkan menurunnya kesuburan tanah. Rata-rata produksi GKP (Gabah Kering Panen) sawah di Subak Kerdung adalah 8 -9 ton/ha, sedangkan di Subak Kepaon hanya mampu 
memperoleh hasil padi sawah sebanyak $7-8$ ton/ha (BPS, 2019).

Berdasarkan latar belakang di atas maka penelitian mengenai evaluasi status kesuburan tanah pada lahan pertanian di Subak Kerdung dan Subak Kepaon Kecamatan Denpasar Selatan sangat penting dilakukan mengingat belum adanya data terbaru status kesuburan tanah di Subak tersebut. Data yang diperoleh dapat dimanfaatkan sebagai data dasar dan sebagai acuan dalam pengelolaan kesuburan tanah untuk budidaya tanaman pertanian agar menguntungkan dan menjadi lahan pertanian pangan yang berkelanjutan. Peraturan Pemerintah No. 12 Tahun 2012 Tentang Insentif Perlindungan Lahan Pertanian Pangan Berkelanjutan, pada pasal 20 huruf b dikatakan bahwa salah satu pertimbangan Pemerintah memberikan Insentif kepada Petani adalah tingkat kesuburan tanah. Pasal 22 (1) Kesuburan tanah sebagaimana dimaksud dalam Pasal 20 huruf b didasarkan pada tingkat kesuburan. (2) Lahan Pertanian Pangan Berkelanjutan dengan tingkat kesuburan rendah diberikan jenis Insentif lebih banyak dibandingkan dengan Lahan Pertanian Pangan Berkelanjutan dengan tingkat kesuburan tinggi. (3) Ketentuan mengenai tingkat kesuburan tanah sebagaimana dimaksud pada ayat (2) berdasarkan kesesuaian lahan pada komoditas tertentu diatur dengan Peraturan Menteri.

Penelitian dilakukan dengan tujuan untuk mengetahui status kesuburan tanah dan faktor pembatasnya serta menyusun arahan pengelolaan kesuburan lahan berdasarkan dengan faktor pembatas kesuburan tanah lokasi penelitian sebagai mendukung program Lahan Pertanian Pangan Berkelanjutan (LP2B). Berdasarkan Peraturan Pemerintah dapat disimpulkan bahwa penentuan status kesuburan tanah pada Subak Kerdung dan Subak Kepaon sangat penting dilakukan untuk memperbaiki kualitas pertanian di Subak Kerdung dan Kepaon sehingga meningkatkan kesejahteraan petani serta mendukung program Lahan Pertanian Pangan Berkelanjutan.

\section{BAHAN DAN METODE}

Penelitian dilaksanakan mulai Agustus sampai dengan November 2020 di Subak Kerdung dan Kepaon, Kecamatan Denpasar Selatan yang masing-masing subak memiliki luas 159,16 ha Subak Kerdung dan 90.3 ha Subak Kepaon. Secara geografis Subak Kerdung terletak pada posisi $8^{\circ} 42^{\prime} 13.0^{\prime \prime} \mathrm{LS}, 115^{\circ} 12^{\prime} 32.1^{\prime \prime} \mathrm{BT}$ dan Subak Kepaon terletak pada posisi $8^{\circ} 42^{\prime} 51.3^{\prime \prime} \mathrm{LS}, 115^{\circ} 11^{\prime} 44.7^{\prime \prime}$ BT. Pada Subak Kerdung dan Subak Kepaon mendapatkan air irigasi yang berasal dari Daerah Aliran Sungai (DAS) Badung. Subak Kerdung dan Kepaon menggunakan benih padi dari varietas C-4 Ciherang.

Subak Kerdung dan Subak Kepaon sangat kondisional terhadap musim. Pada musim hujan hasil produksi di Subak Kerdung dan Kepaon relatif menurun, karena pada musim hujan tingkat serangan penyakit lebih tinggi dibandingkan dengan musim kemarau, selain itu pada musim hujan intensitas radiasi matahari juga lebih rendah dibandingkan musim kemarau yang tentunya kan berpengaruh terhadap proses fotosintesis.

Alat yang digunakan dalam penelitian ini adalah seperangkat software Microsoft Word, software Microsoft Excel dan software QGIS 2.18, serta alat yang digunakan di lapangan berupa pisau lapang, bor belgi plastik, alat tulis, dan google maps.

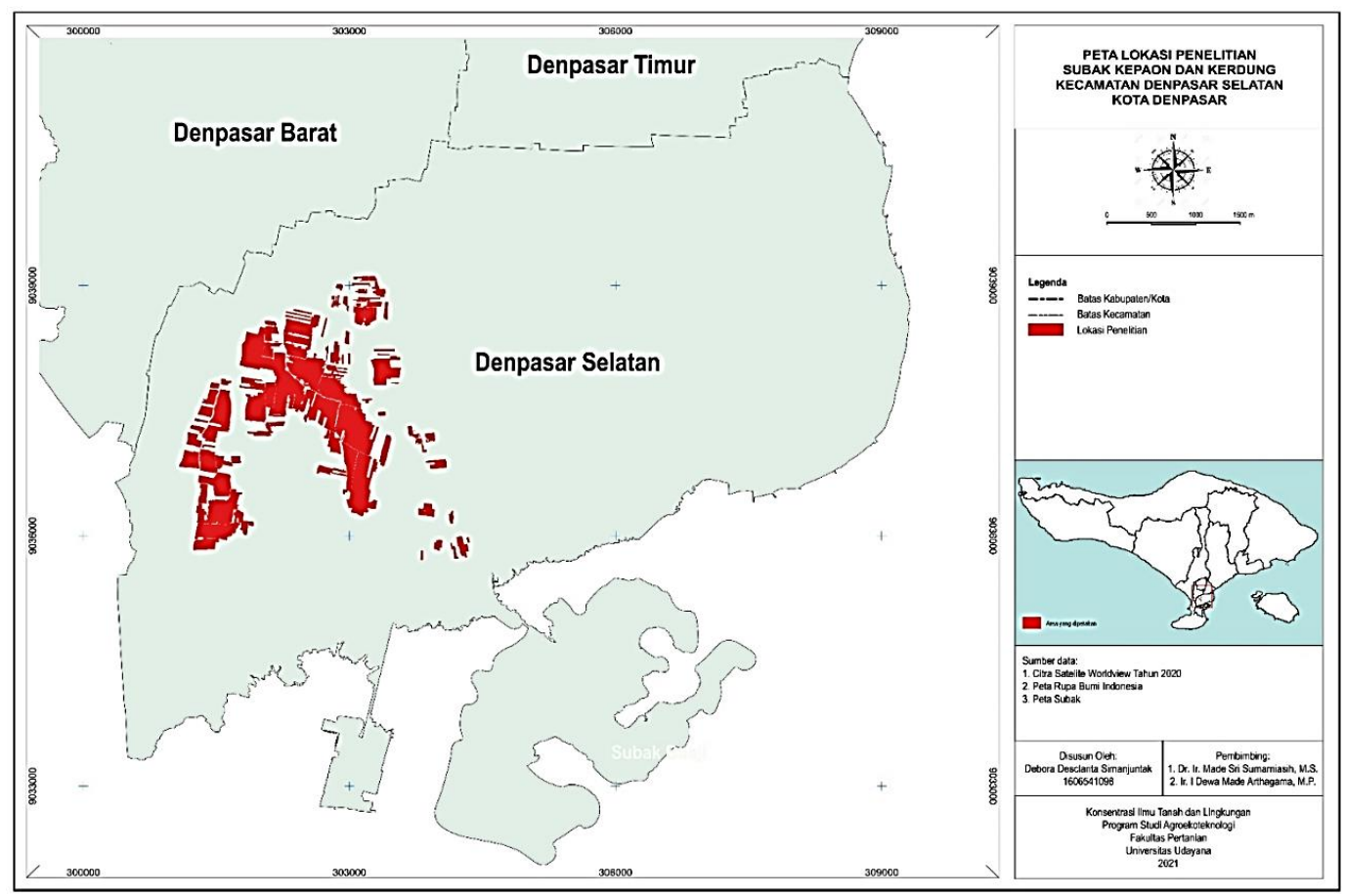

Gambar 1. Peta lokasi penelitian Subak Kerdung dan Subak Kepaon, Denpasar Selatan 
Tabel 1. Kriteria penilaian sifat kimia tanah (PPT, 1995)

\begin{tabular}{|c|c|c|c|c|c|c|c|}
\hline No & Sifat Tanah & SR & $\mathbf{R}$ & $\mathbf{S}$ & $\mathbf{T}$ & ST & \\
\hline 1 & C-organik (\%) & $<1.00$ & $1.00-2.00$ & $2.01-3.00$ & $3.01-5.00$ & \multicolumn{2}{|c|}{$>5.00$} \\
\hline 2 & N-Total $(\%)$ & $<0.10$ & $0.10-0.20$ & $0.21-0.50$ & $0.51-0.75$ & \multicolumn{2}{|c|}{$>0.75$} \\
\hline 3 & $\mathrm{P}_{2} \mathrm{O}_{5} \mathrm{HCL} 25 \%(\mathrm{mg} / 100 \mathrm{~g})$ & $<10$ & $10-20$ & $21-40$ & $41-60$ & \multicolumn{2}{|c|}{$>60$} \\
\hline 4 & $\mathrm{~K}_{2} \mathrm{O}$ HCL $25 \%(\mathrm{mg} / 100 \mathrm{~g})$ & $<10$ & $10-20$ & $21-40$ & $41-60$ & \multicolumn{2}{|c|}{$>60$} \\
\hline 5 & KTK (CEC) & $<5$ & $5-16$ & $17-24$ & $25-40$ & \multicolumn{2}{|c|}{$>40$} \\
\hline 6 & Kejenuhan Basa (\%) & $<20$ & $20-35$ & $36-50$ & $51-70$ & \multicolumn{2}{|c|}{$>70$} \\
\hline 7 & Kadar Garam $(\%)$ & $0-2.0$ & $2.1-4.0$ & $4.1-8.0$ & $8.1-16.0$ & \multicolumn{2}{|c|}{$>16.0$} \\
\hline \multirow[t]{2}{*}{8} & $\mathrm{pH}\left(\mathrm{H}_{2} \mathrm{O}\right)$ & $<4.5$ & $4.5-5.5$ & $5.6-6.5$ & $6.6-7.5$ & 7.6-8.5 & $>8.5$ \\
\hline & & $\begin{array}{l}\text { Sangat } \\
\text { Masam }\end{array}$ & Masam & Agak Masam & Netral & $\begin{array}{c}\text { Agak } \\
\text { Alkalis }\end{array}$ & Alkalis \\
\hline
\end{tabular}

Keterangan: $\mathrm{ST}=$ Sangat Tinggi; $\mathrm{T}=$ Tinggi; $\mathrm{S}=$ Sedang; $\mathrm{R}=$ Rendah; $\mathrm{SR}=$ Sangat Rendah Sumber : (PPT, 1995).

Tabel 2. Kombinasi sifat kimia Tanah dan Status Kesuburan (PPT, 1995)

\begin{tabular}{|c|c|c|c|c|}
\hline No & KTK & Kejenuhan Basa & P2O5, K2O, C-organik & Status Kesuburan \\
\hline 1 & $\mathrm{~T}$ & $\mathrm{~T}$ & $\geq 2 \mathrm{~T}$ tanpa $\mathrm{R}$ & Tinggi \\
\hline 2 & $\mathrm{~T}$ & $\mathrm{~T}$ & $\geq 2 \mathrm{~T}$ dengan $\mathrm{R}$ & Sedang \\
\hline 3 & $\mathrm{~T}$ & $\mathrm{~T}$ & $\geq 2 \mathrm{~S} \tan p a \mathrm{R}$ & Tinggi \\
\hline 4 & $\mathrm{~T}$ & $\mathrm{~T}$ & $\geq 2 \mathrm{~S}$ dengan $\mathrm{R}$ & Sedang \\
\hline 5 & $\mathrm{~T}$ & $\mathrm{~T}$ & $\mathrm{~T}>\mathrm{S}>\mathrm{R}$ & Sedang \\
\hline 6 & $\mathrm{~T}$ & $\mathrm{~T}$ & $\geq 2 \mathrm{R}$ dengan $\mathrm{T}$ & Sedang \\
\hline 7 & $\mathrm{~T}$ & $\mathrm{~T}$ & $\geq 2 \mathrm{R}$ dengan $\mathrm{S}$ & Rendah \\
\hline 8 & $\mathrm{~T}$ & $S$ & $\geq 2 \mathrm{~T}$ tanpa $\mathrm{R}$ & Tinggi \\
\hline 9 & $\mathrm{~T}$ & S & $\geq 2 \mathrm{~T}$ dengan $\mathrm{R}$ & Sedang \\
\hline 10 & $\mathrm{~T}$ & $S$ & $\geq 2 \mathrm{~S}$ & Sedang \\
\hline 11 & $\mathrm{~T}$ & $S$ & Kombinasi lain & Rendah \\
\hline 12 & $\mathrm{~T}$ & $\mathrm{R}$ & $\geq 2 \mathrm{~T}$ tanpa $\mathrm{R}$ & Sedang \\
\hline 13 & $\mathrm{~T}$ & $\mathrm{R}$ & $\geq 2 \mathrm{~T}$ dengan $\mathrm{R}$ & Rendah \\
\hline 14 & $\mathrm{~T}$ & $\mathrm{R}$ & Kombinasi lain & Rendah \\
\hline 15 & $S$ & $\mathrm{~T}$ & $\geq 2 \mathrm{~T}$ tanpa $\mathrm{R}$ & Sedang \\
\hline 16 & S & $\mathrm{T}$ & $\geq 2 \mathrm{~S}$ tanpa $\mathrm{R}$ & Sedang \\
\hline 17 & S & $\mathrm{T}$ & Kombinasi lain & Rendah \\
\hline 18 & S & S & $\geq 2 \mathrm{~T}$ tanpa $\mathrm{R}$ & Sedang \\
\hline 19 & S & $S$ & $\geq 2 \mathrm{~S}$ tanpa $\mathrm{R}$ & Sedang \\
\hline 20 & S & S & Kombinasi lain & Rendah \\
\hline 21 & S & $\mathrm{R}$ & $3 \mathrm{~T}$ & Sedang \\
\hline 22 & S & $\mathrm{R}$ & Kombinasi lain & Rendah \\
\hline 23 & $\mathrm{R}$ & $\mathrm{T}$ & $\geq 2 \mathrm{~T}$ tanpa $\mathrm{R}$ & Sedang \\
\hline 24 & $\mathrm{R}$ & $\mathrm{T}$ & $\geq 2 \mathrm{~T}$ dengan $\mathrm{R}$ & Rendah \\
\hline 25 & $\mathrm{R}$ & $\mathrm{T}$ & $\geq 2 \mathrm{~S}$ tanpa $\mathrm{R}$ & Sedang \\
\hline 26 & $\mathrm{R}$ & $\mathrm{T}$ & Kombinasi lain & Rendah \\
\hline 27 & $\mathrm{R}$ & S & $\geq 2 \mathrm{~T}$ tanpa $\mathrm{R}$ & Sedang \\
\hline 28 & $\mathrm{R}$ & S & Kombinasi lain & Rendah \\
\hline 29 & $\mathrm{R}$ & $\mathrm{R}$ & Semua kombinasi & Rendah \\
\hline 30 & SR & $\mathrm{T}, \mathrm{S}, \mathrm{R}$ & Semua kombinasi & Sangat Rendah \\
\hline
\end{tabular}

Keterangan: $\mathrm{ST}=$ Sangat Tinggi; $\mathrm{T}=$ Tinggi; $\mathrm{S}=$ Sedang; $\mathrm{R}=$ Rendah; $\mathrm{SR}=$ Sangat Rendah

Sumber : (PPT Bogor, 1995) 
Tabel 3. Klasifikasi status kesuburan tanah.

\begin{tabular}{|c|c|c|c|c|c|c|c|c|}
\hline No & Satuan Lahan Homogen (SLH) & $\begin{array}{l}\text { Lokasi } \\
\text { Sampel }\end{array}$ & $\begin{array}{c}\mathrm{KTK} \\
(\mathrm{me} / 100 \mathrm{~g})\end{array}$ & $\begin{array}{l}\mathrm{KB} \\
(\%)\end{array}$ & $\begin{array}{c}\text { P-total } \\
(\mathrm{mg} / 100 \mathrm{~g})\end{array}$ & $\begin{array}{c}\text { K-total } \\
(\mathrm{mg} / 100 \mathrm{~g})\end{array}$ & $\begin{array}{c}\mathrm{C}- \\
\text { organik } \\
(\%)\end{array}$ & $\begin{array}{c}\text { Status } \\
\text { Kesuburan }\end{array}$ \\
\hline 1 & I & $\begin{array}{c}\text { Subak } \\
\text { Kerdung }\end{array}$ & $\begin{array}{l}43,05 \\
\text { ST }\end{array}$ & $\begin{array}{c}80,83 \\
\text { ST }\end{array}$ & $\begin{array}{c}27,54 \\
S\end{array}$ & $\begin{array}{c}42,64 \\
\mathrm{~T}\end{array}$ & $\begin{array}{l}5,24 \\
\text { ST }\end{array}$ & Tinggi \\
\hline 2 & II & $\begin{array}{c}\text { Subak } \\
\text { Kerdung }\end{array}$ & $\begin{array}{c}35,30 \\
\mathrm{~T}\end{array}$ & $\begin{array}{c}92,50 \\
\text { ST }\end{array}$ & $\begin{array}{c}22,48 \\
\mathrm{~S}\end{array}$ & $\begin{array}{c}46,75 \\
\mathrm{~T}\end{array}$ & $\begin{array}{c}4,44 \\
\mathrm{~T}\end{array}$ & Tinggi \\
\hline 3 & III & $\begin{array}{c}\text { Subak } \\
\text { Kerdung }\end{array}$ & $\begin{array}{c}17,98 \\
\mathrm{~S}\end{array}$ & $\begin{array}{c}93,50 \\
\text { ST }\end{array}$ & $\begin{array}{c}33,17 \\
\mathrm{~S}\end{array}$ & $\begin{array}{c}42,68 \\
\mathrm{~T}\end{array}$ & $\begin{array}{l}7,06 \\
\text { ST }\end{array}$ & Sedang \\
\hline 4 & IV & $\begin{array}{c}\text { Subak } \\
\text { Kepaon }\end{array}$ & $\begin{array}{c}24,42 \\
S\end{array}$ & $\begin{array}{c}63,72 \\
\mathrm{~T}\end{array}$ & $\begin{array}{c}25,03 \\
S\end{array}$ & $\begin{array}{c}40,15 \\
\mathrm{~T}\end{array}$ & $\begin{array}{c}4,35 \\
\mathrm{~T}\end{array}$ & Sedang \\
\hline 5 & $\mathrm{~V}$ & $\begin{array}{c}\text { Subak } \\
\text { Kepaon }\end{array}$ & $\begin{array}{c}31,13 \\
\mathrm{~T}\end{array}$ & $\begin{array}{c}52,07 \\
\mathrm{~T}\end{array}$ & $\begin{array}{c}30,95 \\
\text { S }\end{array}$ & $\begin{array}{c}43,67 \\
\mathrm{~T}\end{array}$ & $\begin{array}{l}5,15 \\
\text { ST }\end{array}$ & Tinggi \\
\hline
\end{tabular}

Keterangan : $\mathrm{S}=$ Sedang, $\mathrm{T}=$ Tinggi, $\mathrm{ST}=$ Sangat Tinggi

Sumber : (PPT Bogor, 1995)

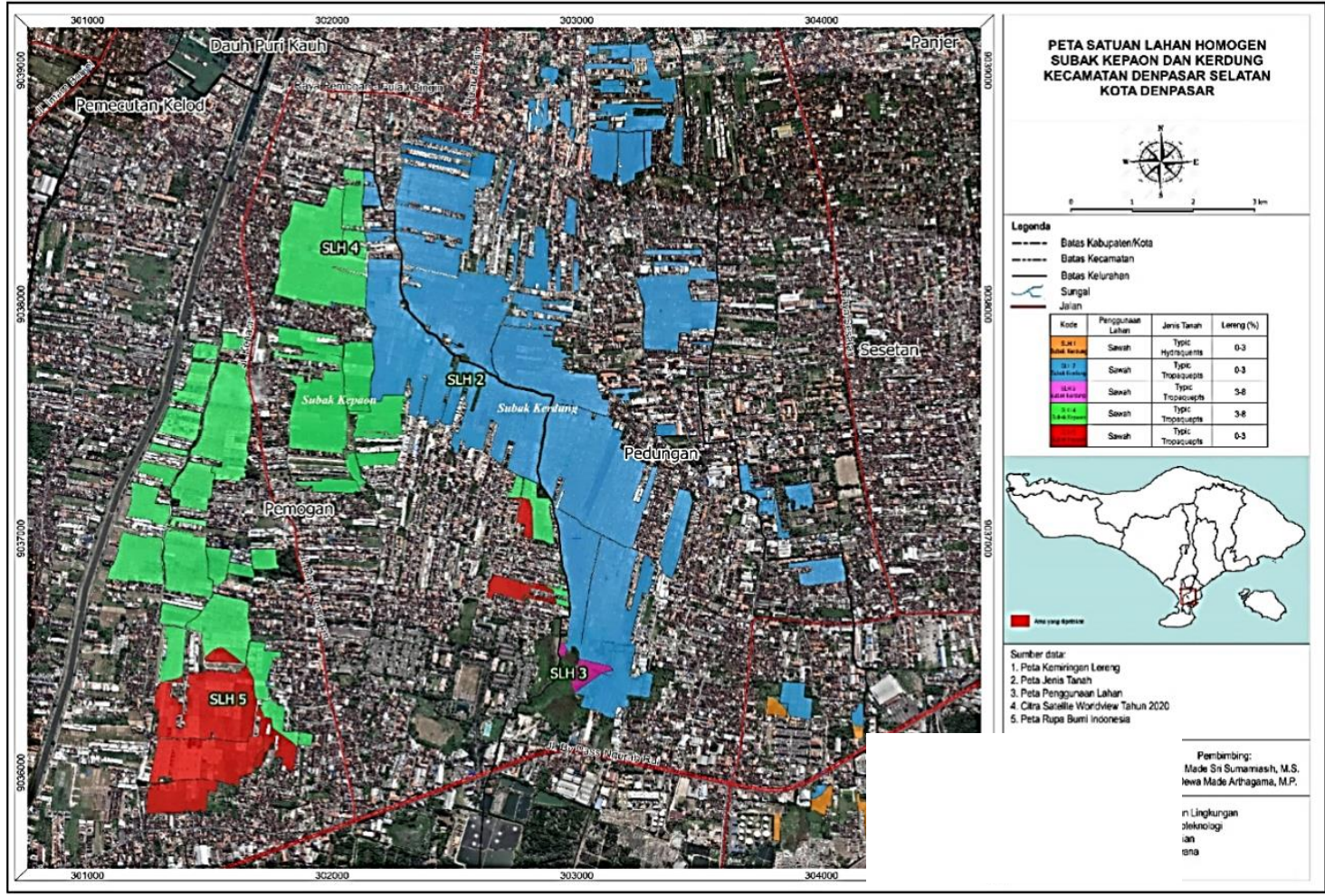

Gambar 2. Peta satuan lahan homogen Subak Kerdung dan Subak Kepaon, Denpasar Selatan.

Bahan yang digunakan dalam penelitian ini antara lain Peta Penggunaan Lahan skala 1 : 25.000, Peta Tanah Semi Detail skala 1 : 50.000, Peta Kemiringan Lereng skala 1 : 50.000, Peta Rekomendasi Lahan Pertanian Pangan Berkelanjutan (LP2B) Kota Denpasar skala 1 : 50.000, dan sampel tanah serta zat-zat kimia.

Adapun pelaksanaan penelitian yang dilakukan pada penelitian ini adalah sebagai berikut:

\section{Delineasi Satuan Lahan Homogen}

Satuan Lahan Homogen (SLH) dideliniasi berdasarkan tumpang susun peta dasar Citra pengindraan jauh Denpasar Selatan skala 1:50.000 yang bersumber dari google earth. Peta Penggunaan Lahan di Subak Kerdung dan Subak Kepaon skala $1: 25.000$, Peta Tanah Semi Detail di Subak Kerdung dan Subak Kepaon skala $1: 50.000$, Peta kemiringan lereng pada Subak Kerdung dan Subak Kepaon 
skala 1 : 50.000, dan Peta Rekomendasi Lahan Pertanian Pangan Berkelanjutan (LP2B) Kota Denpasar skala 1 : 50. Berdasarkan hasil tumpang susun diperoleh lima Satuan Lahan Homogen yang disajikan pada Gambar 2. Hasil tumpang susun peta-peta tersebut akan digunakan sebagai peta kerja dalam pengambilan sampel. Pembuatan peta SLH menggunakan software QGIS 2.18.

\section{Survei lapangan dan pengambilan sampel}

Survei Lapangan merupakan kegiatan tahap pengambilan sampel tanah dengan mencocokkan peta SLH dengan kondisi di lapangan, kemudian dalam survei lapangan dilakukan pengamatan visual kondisi lahan seperti lereng, jenis tanah, dan mengukur $\mathrm{pH}$ tanah di lapangan. Setiap SLH dilakukan pengambilan sampel tanah secara komposit dengan menentukan titik-titik pengambilan sampel tanah secara acak, tetapi menyebar rata dan setiap titik yang diambil mewakili daerah sekitarnya. Pengambilan sampel tanah pada masingmasing SLH diambil pada kedalaman 0-20 cm.

\section{Preparasi dan uji tanah}

Preparasi sampel tanah merupakan bagian mempersiapkan sampel melalui proses pengeringan, penghancuran, dan pengayakan agar dapat dianalisis menggunakan instrumen sesuai parameter kesuburan tanah yang digunakan untuk menilai status kesuburan tanah, yaitu KTK; KB; C-organik; kadar P-total, K-total dan pH serta menentukan kadar air dan tekstur tanah sesuai petunjuk teknis evaluasi kesuburan tanah. Sampel tanah yang sudah disiapkan kemudian dianalisis di Laboratorium Ilmu Tanah dan Lingkungan untuk menetapkan sifat kimia tanah. hasil analisis yang didapat kemudian dicocokkan berdasarkan kriteria penilaian sifat kimia tanah menurut PPT (1995) yang disajikan pada Tabel 1. Penentuan status kesuburan tanah lokasi penelitian dilakukan analisis data berdasarkan kombinasi sifat kimia tanah dan status kesuburan menurut PPT (1995) yang disajikan pada Tabel 2.

\section{Analisis data dan evaluasi status kesuburan tanah}

Penilaian status kesuburan tanah meliputi hasil data sifat kimia tanah yang dicocokkan dengan Kriteria Status Kesuburan Tanah (PPT, 1995) pada Tabel 2. Selanjutnya membuat anjuran pemupukan berimbang spesifik lokasi untuk tanah sawah sesuai dengan status kesuburan tanah yang telah diperoleh berdasarkan Permentan No. 40 Tahun 2007 tentang Rekomendasi Pemupukan N, P, dan K Pada Padi Sawah Spesifik Lokasi.

\section{Pembuatan peta status kesuburan tanah}

Pembuatan peta berfungsi dalam mempermudah pembacaan tanpa menggunakan angka-angka yang sangat rumit, serta mempermudah untuk mengingatnya. Pembuatan peta status kesuburan tanah di Subak Kerdung dan Subak Kepaon Denpasar Selatan dengan menggunakan perangkat QGIS 2.18.

\section{HASIL DAN PEMBAHASAN}

Hasil penelitian berdasarkan sifat kimia tanah dan kriteria penetapan status kesuburan tanah berdasarkan PPT (1995) diperoleh dua kelas status kesuburan tanah yaitu sedang dan tinggi.

\section{Kapasitas Tukar Kation (KTK) tanah}

Nilai Kapasitas Tukar Kation (KTK) tanah di Subak Kerdung dan Subak Kepaon memiliki status sedang, tinggi dan sangat tinggi dengan nilai antara 17,98 me/100 g sampai 43,05 me/100 g (Tabel 3). Tingginya status KTK tanah di Subak Kerdung dan Subak Kepaon disebabkan pH tanah yang netral dan pengembalian sumber bahan organik seperti jerami padi yang secara rutin dilakukan, serta kandungan liat yang tinggi tipe liat adalah 2:1 monmorilonit. Tanah yang didominasi oleh fraksi liat memiliki kapasitas pertukaran ion dan kapasitas yang memegang air tinggi, oleh karena itu tanah yang didominasi oleh fraksi liat memiliki stabilitas agregat yang tinggi karena adanya ikatan dalam partikel tanah (Sukisno et al., 2011). Penyebab KTK SLH III dan IV tanah tergolong sedang adalah tekstur pada SLH didominasi oleh pasir sebanyak $37,45 \%$ pada SLH III dan $41 \%$ pada SLH IV. Tingginya KTK dipengaruhi oleh kadar liat dan tipe liat $2: 1$. Foth (1998) menyatakan bahwa fraksi pasir dan debu menampilkan ikatan negatif yang tidak begitu baik karena luas permukaan spesifiknya yang rendah sehingga pasir mempunyai kapasitas tukar kation yang rendah.

1. Kejenuhan Basa (KB)

Nilai Kejenuhan Basa (KB) tanah di Subak Kerdung dan Subak Kepaon memiliki status tinggi dengan nilai antara $52,07 \%-93,50 \%$ (Tabel 3). Status KB tanah tersebut dipengaruhi oleh kondisi $\mathrm{pH}$ tanah. Nilai $\mathrm{pH}$ tanah di Subak Kerdung dan Kepaon yaitu 7,10 - 7,55. Status KB tinggi juga dapat diakibatkan oleh keadaan lereng $0-8 \%$ yang mendominasi wilayah di Subak Kerdung dan Kepaon sehingga kecil kemungkinannya terjadi erosi dan keadaan ini memberikan pengaruh sangat kecil terhadap hilangnya kation-kation basa, hal ini sesuai dengan penelitian Pinatih dkk (2015). Tingginya nilai KB tanah menunjukkan banyak kation-kation basa seperti $\mathrm{Ca}, \mathrm{Mg}, \mathrm{K}$ dan $\mathrm{Na}$ yang terdapat di dalam tanah yang berarti ketersediaan kation-kation basa cukup banyak untuk keperluan tanaman dari segi hara tanah (Tan, 1991).

\section{C-organik Tanah}

Nilai C-organik pada tanah di Subak Kerdung dan Subak Kepaon memiliki status tinggi sampai sangat tinggi dengan nilai antara 4,35 \% sampai 7,06 \% (Tabel 3). Kandungan C-organik pada lokasi penelitian tergolong tinggi kemungkinan disebabkan sistem usaha tani sudah dikelola dengan baik. Pengembalian sumber bahan organik seperti jerami padi telah dilakukan sehingga kandungan C-organik yang ada di dalam tanah tinggi. Tanaman sisa-sisa panen yang dimasukkan ke dalam tanah dapat berperan sebagai salah satu sumber utama bahan organik tanah (Hardjowigeno, 2003).

3. Fosfor $\left(\mathrm{P}_{2} \mathrm{O}_{5}\right)$ Total Tanah

Nilai P-total pada tanah di Subak Kerdung dan Subak Kepaon memiliki status sedang dengan nilai antara 22,48 
mg/100 g sampai 33,17 mg/100 g (Tabel 3). Pada lokasi penelitian nilai $\mathrm{pH}>7,0$ membuat ketersediaan $\mathrm{P}$ tergolong sedang. Fosfor paling mudah diserap oleh tanaman pada $\mathrm{pH}$ sekitar netral $(6,0-7,0)$ yang berarti tanah pada lokasi penelitian memiliki kandungan unsur hara $\mathrm{P}$ yang masih cukup dalam penyediaannya untuk kebutuhan tanaman. Namun defisiensi $\mathrm{P}$ masih tetap menjadi pembatas utama produksi tanaman pangan (Lombi et al., 2004).

4. Kalium $\left(\mathrm{K}_{2} \mathrm{O}\right)$ Total Tanah

Nilai K-total pada tanah di Subak Kerdung dan Subak Kepaon memiliki status tinggi dengan nilai antara 40,15 $\mathrm{mg} / 100 \mathrm{~g}$ sampai 46,75 mg/100 g (Tabel 3). Tingginya nilai KTK dapat mempengaruhi larutan tanah untuk dapat melepaskan kalium dan dapat menurunkan potensi pencucian kalium di dalam tanah. Kandungan $\mathrm{K}$ total dalam tanah dipengaruhi oleh beberapa faktor, seperti tipe koloid tanah, $\mathrm{pH}$ tanah dan tingkat pelapukan (Hanafiah, 2008).

1. Reaksi Tanah (pH Tanah)

Hasil penelitian menunjukkan $\mathrm{pH}$ tanah di Subak Kerdung dan Subak Kepaon tergolong netral (7,10 7,51) yang membuat tanaman mampu optimal dalam penyerapan unsur hara yang terdapat dalam pupuk karena pada kondisi $\mathrm{pH}$ netral unsur hara mudah larut dalam air sehingga unsur hara tersebut pada kondisi tersedia.

\section{Tekstur}

Hasil analisis tekstur tanah di Subak Kerdung dan Kepaon ditemukan 3 kelas tekstur tanah yaitu tekstur lempung, lempung berliat, dan lempung berdebu. Tekstur tanah sawah Subak Kerdung dan Kepaon menunjukkan bahwa data analisis kimia tanah meliputi KTK, KB, C-organik, P-total, dan K-total yang disajikan berbanding lurus dengan keadaan tekstur tanah pada lahan sawah di Subak Kerdung dan Subak Kepaon.

3. Kadar Air Tanah

Berdasarkan hasil kadar air tanah pada Subak Kerdung dan Subak Kepaon dapat disimpulkan bahwa kelas tekstur tanah berbanding lurus dengan hasil kadar air tanah. Tanah bertekstur liat memiliki kemampuan yang lebih besar dalam memegang air daripada tanah bertekstur pasir hal ini terkait dengan luas permukaan adsorptifnya. Semakin halus teksturnya akan semakin besar kapasitas menyimpan airnya. Semakin halus teksturnya akan semakin besar kapasitas menyimpan airnya. Pada satuan unit lahan masing-masing subak dengan nilai 8,06 \% - 9,63\% di Subak Kepaon dan 10,31\% - 16,76 \% di Subak Kerdung. Hal ini menandakan pelapukan mineral dan bahan organik pada Subak Kerdung sedikit lebih cepat dibandingkan dengan Subak Kepaon.

4. Evaluasi Status Kesuburan Tanah

Berdasarkan hasil evaluasi status kesuburan tanah di Subak Kerdung dan Kepaon Denpasar Selatan dengan mencocokkan sifat kimia tanah (Tabel 1) dengan kriteria status kesuburan tanah (Tabel 2) dapat dikelompokkan menjadi 2 status kesuburan yaitu sedang dan tinggi (Tabel 3). Subak Kerdung dan Kepaon yang mempunyai status kesuburan sedang terdapat pada dua SLH yaitu SLH III (Subak Kerdung) dan IV (Subak
Kepaon), sedangkan status kesuburan tanah tinggi terdapat pada SLH I (Subak Kerdung), II (Subak Kerdung), dan SLH V (Subak Kepaon) (Gambar 3).

5. Arahan Pengelolaan Kesuburan Tanah

Secara umum kendala yang ditemui pada lima SLH yang memiliki status kesuburan sedang yaitu adanya faktor pembatas P-total karena lokasi penelitian bahan induk terdiri dari endapan Aluvial dan KTK yang tergolong sedang karena mempunyai tipe mineral liat $2: 1$. Alternatif pengelolaan yang perlu dilakukan adalah dengan penambahan bahan organik berupa pengembalian sisa panen dan pupuk kandang secara rutin agar kesuburan tanah dapat tetap terpelihara dengan baik dan berkelanjutan. Kandungan C-organik pada setiap lahan memang tergolong tinggi, namun pemberian bahan organik tetap diperlukan agar produksi dan kualitas tanah tetap terjaga. Brady (1984) menyatakan bahwa bahan organik sangat mempengaruhi ketersediaan P. Dekomposisi bahan organik menghasilkan asam organik dan humus yang secara efektif mengurangi penjerapan $\mathrm{P}$ anorganik sehingga menjadi P-tersedia bagi tanaman. Dosis perlakuan pupuk P (SP-36) yang digunakan adalah dosis $\mathrm{P}$ untuk status $\mathrm{P}$ tanah sedang, yaitu pada kisaran 50 sampai $75 \mathrm{~kg} / \mathrm{ha}$ SP-36 (Hardjowigeno et al., 2004), Sedangkan dosis perlakuan pupuk kandang sapi menggunakan kisaran dosis 5 sampai 15 ton/ha dengan acuan dosis optimal berdasarkan hasil penelitian Joy (2000), yaitu pada kisaran 7,5 ton/ha.

Kapasitas Tukar Kation yang tergolong sedang disebabkan oleh kelas tekstur lempung berliat dengan kandungan pasir 37,45\% - 41,72\% sehingga pertukaran kation tidak cukup baik, karena salah satu yang sangat mempengaruhi KTK tanah adalah tekstur tanah dan tipe liatnya. Bahan organik merupakan salah satu pembenah tanah yang telah dirasakan manfaatnya dalam perbaikan sifat-sifat tanah baik sifat fisik, kimia dan biologi tanah. Secara fisik memperbaiki struktur tanah, menentukan tingkat perkembangan struktur tanah dan berperan pada pembentukan agregat tanah (Tate, 1987 dalam Rajiman et al., 2008), meningkatkan daya simpan lengas karena bahan organik mempunyai kapasitas menyimpan lengas yang tinggi (Stevenson, 1982 dalam Rajiman et al., 2008).

6. Peta Status Kesuburan Tanah di Subak Kerdung dan Subak Kepaon

Peta status kesuburan tanah merupakan hasil akhir yang berisikan informasi tentang status kesuburan, luas, serta sebaran kesuburan tanah pada Subak Kerdung dan Kepaon yang dipetakan. Subak Kerdung dan Subak Kepaon memiliki status kesuburan tanah sedang dan tinggi. Status kesuburan yang sedang yaitu SLH III (Subak Kerdung) dan IV (Subak Kepaon). Sedangkan status kesuburan yang tinggi terdapat pada SLH I (Subak Kerdung), II (Subak Kerdung), dan V (Subak Kepaon). Tinggi rendahnya status kesuburan tanah dipengaruhi oleh $\mathrm{pH}$, bahan organik, jumlah dan ketersediaan unsur hara, KTK, dan KB. 


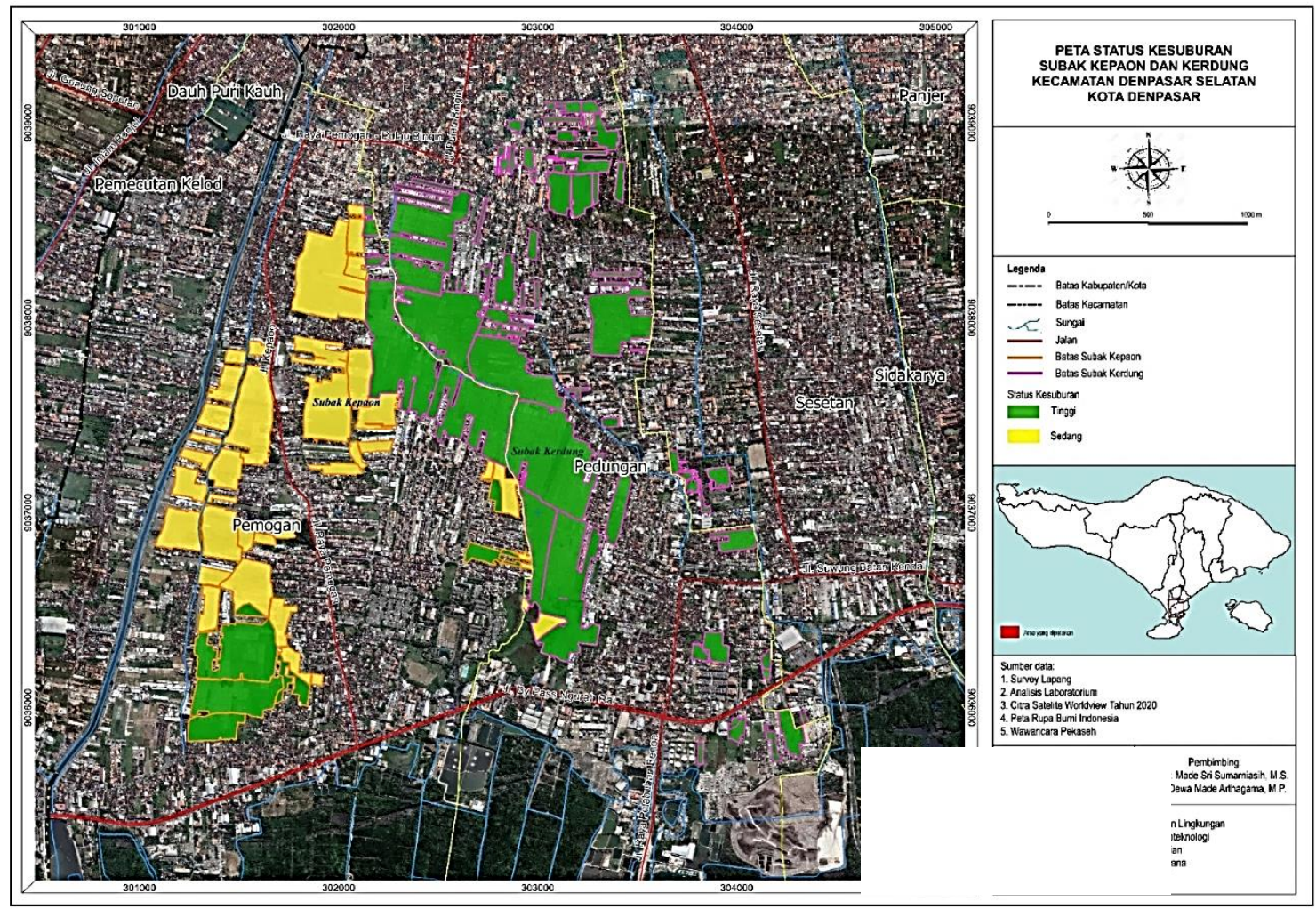

Gambar 3. Peta Status Kesuburan Tanah Subak Kerdung dan Subak Kepaon, Denpasar Selatan.

Berdasarkan peta status kesuburan tanah pada Subak Kerdung dan Subak Kepaon (Gambar 3), maka Subak Kerdung lebih subur dari Subak Kepaon.

\section{KESIMPULAN}

Berdasarkan hasil penelitian dapat disimpulkan bahwa Subak Kerdung dan Subak Kepaon Denpasar Selatan memiliki status kesuburan tanah tinggi pada SLH I (Subak Kerdung), II (Subak Kerdung), dan V (Subak Kepaon), sedangkan pada SLH III (Subak Kerdung) dan IV (Subak Kepaon) memiliki status kesuburan sedang. Parameter kesuburan tanah yang menjadi faktor pembatas dalam status kesuburan tanah di Subak Kerdung dan Subak Kepaon yaitu kandungan P-total dan KTK tergolong sedang yang terdapat pada SLH III dan SLH IV. Arahan pengelolaan kesuburan tanah perlu adanya pemberian bahan organik berupa pengembalian sisa panen dan pupuk kandang serta pupuk yang mengandung unsur $\mathrm{P}$ seperti pupuk SP-36 ke dalam tanah.

\section{DAFTAR PUSTAKA}

Badan Pusat Statistika Denpasar Selatan. (2019). Kecamatan Denpasar Selatan Dalam Angka 2019. Badan Pusat Statistik Kota Denpasar.

Brady, N.C. (1984). The Nature and Properties of Soils (10th edition). MacMillan Publ. Co. New York. USA.

Hanafiah, K. A. (2008). Dasar-dasar Ilmu Tanah. Jakarta: PT. Raja Grafindo Persada
Hardjowigeno S. (2003). Dasar-dasar Ilmu Tanah. Rajawali Press.

Joy, B. (2000). Adsorpsi-Desorpsi P dan Serapan Fosfat, Hasil Kedelai serta Beberapa Sifat Kimia Tanah sebagai Pengaruh Amelioran dan Pupuk Fosfat pada Tanah Typic Kanhapludults dan Typic Eutrudepts. Universitas Padjadjaran. Bandung. Disertasi.

Lombi, E., M.J. McLaughlin, C. Johnston, R.D. Armstrong, and R.E. Holoway. (2004). Mobility, solubility, and lability of fluid and granular forms of $\mathrm{P}$ fertiliser in calcareous and non-calcareous soils under laboratory conditions. Plant and Soil 269:25-34.

Tan, K. H. (1991). Dasar-dasar Kimia Tanah. Gajah Mada University Press. Yogyakarta. Terjemahan: D. H. Goenadi. 259.

Pinatih, I. D. A. Sri Purnami, Tati, B. K., dan Ketut, D. S. (2015). Evaluasi status kesuburan tanah pada lahan pertanian di Kecamatan Denpasar Selatan. E-journal Agroekoteknologi Tropika 4(4), 282-292.

Pusat Penelitian Tanah. (1995). Kombinasi Beberapa Sifat Kimia Tanah dan Status Kesuburannya. Bogor.

Rajiman., Prapto Yudono, Endang Sulistyaningsih, dan Eko Hanudin. (2008). Pengaruh Pembenah Tanah Terhadap Sifat Fisika TanahDan Hasil Bawang Merah Pada Lahan Pasir Pantai BugelKabupaten Kulon Progo. Agrin. 12(1), 67-77.

Sukisno, K. S. Hindarto., Hasanudin., dan A. H. Wicaksono. (2011). Pemetaan Potensi dan Status Kerusakan Tanah untuk Mendukung Produktivitas Biomassa di 
Kabupaten Lebong. Program Studi Ilmu Tanah, Fakultas Pertanian Universitas Bengkulu. Yamani, A. (2010). Kajian Tingkat Kesuburan Tanah pada
Hutan Lindung Gunung Sebatung di Kabupaten Kota Baru Kalimantan Selatan. Jurnal Hujan Tropis, 11 (29), 32-37. 